\title{
Group interpersonal psychotherapy may be as effective as group cognitive behavioural therapy for overweight people with binge eating disorder
}

Wilfley $D$, Welch $R$, Stein $R$ et al. A randomized comparison of group cognitive-behavioral therapy and group interpersonal psychotherapy for the treatment of overweight individuals with binge-eating disorder. Archives of General Psychiatry 2002 Aug;59:713-21.

QUESTION: How effective is group cognitive behavioural therapy compared to group interpersonal psychotherapy for reducing binge eating in overweight people?

\section{Design}

Randomised trial with centralised allocation. Outcome assessors were not fully blind to treatment allocation, but there was ongoing supervision to standardise assessment.

\section{Setting}

Eating disorder clinics in Connecticut and San Diego, USA; timeframe not specified.

\section{Participants}

Participants were 162 overweight people meeting DSM-IV criteria for binge eating disorder, recruited with media promotions. All were aged between 18 and 65 years (mean 45 years) and had body mass index between 27 and $48 \mathrm{~kg} / \mathrm{m}^{2} .83 \%$ women; $92 \%$ white. Exclusion criteria were pregnancy or plans to become pregnant; taking weight affecting or psychotropic medications; psychiatric conditions warranting immediate treatment; current enrolment in psychotherapy or a weight loss programme.

\section{Intervention}

20 weekly 90 -minute sessions of group cognitive behavioural therapy (CBT) or group interpersonal psychotherapy (IPT). Each intervention also included 3 individual sessions.

\section{Main outcome measures}

Binge eating and associated eating disorder psychopathology was assessed using the Eating Disorder Examination immediately following treatment and 4, 8, and 12 months later. General psychological functioning and weight were also measured at 4 month intervals up to 1 year.

Source of funding:

US National Institute

of Mental Health.

For correspondence: $D$ Wilfley, San Diego Joint Doctoral Clinical Psychology Training Program, USA.

dwilfley@ psychology.sdsu.edu
Binge eating recovery rates post-treatment and at 1 year for overweight people receiving cognitive behavioural therapy or overweight people receiving
interpersonal psychotherapy

\begin{tabular}{lcc}
$\begin{array}{l}\text { Binge eating } \\
\text { recovery }\end{array}$ & $\begin{array}{c}\text { Cognitive } \\
\text { behavioural } \\
\text { therapy \% }\end{array}$ & $\begin{array}{c}\text { Interpersonal } \\
\text { psychotherapy \% }\end{array}$ \\
\hline Post treatment & 79 & 73 \\
\hline 1 year follow up & 59 & 62 \\
\hline
\end{tabular}

\section{Main results}

Binge eating recovery rates were equivalent between groups directly after treatment and at 1-year follow up (table). There were no differences between groups in associated eating disorders and psychiatric symptoms or maintenance of gains during follow up.

\section{Conclusions}

Group interpersonal psychotherapy and group cognitive behavioural therapy are equally effective for reducing binge eating among overweight people.

\section{COMMENTARY}

There is a growing body of evidence about treatment strategies for binge eating disorder. Research has found both group cognitive behavioural therapy (CBT) and group interpersonal therapy (IPT) to be effective. Each strategy may engage different mechanisms. This well designed study examined the mechanisms involved in CBT and IPT. Overall response rates in both groups were high, but there were no differences between groups in improvements on associated variables (for example, interpersonal problems or dietary restraint). Participants who achieved abstinence lost more weight than the non-abstinent group, but this effect was modest.

The findings suggest that group CBT and IPT are both useful clinical approaches for binge eating disorder. Evidence for treatment-specific mechanisms for improvement was not found, so the search for treatment specificity continues. One limitation of the study is that CBT and IPT may not be widely available, but this is more a criticism of existing training programmes than of the study itself.

Scott J Crow, MD Associate Professor of Psychiatry University of Minnesota Minneapolis, USA 